\title{
Effect of ammonia addition on microstructure and wear performance of carbonitrided high carbon bearing steel AISI 52100
}

Liu, Bin; Wang, Bo; Gu, Jianfeng

Published in:

Surface and Coatings Technology

Link to article, DOI:

10.1016/j.surfcoat.2019.01.019

Publication date:

2019

Document Version

Peer reviewed version

Link back to DTU Orbit

Citation (APA):

Liu, B., Wang, B., \& Gu, J. (2019). Effect of ammonia addition on microstructure and wear performance of carbonitrided high carbon bearing steel AISI 52100. Surface and Coatings Technology, 361, 112-118. https://doi.org/10.1016/..surfcoat.2019.01.019

\section{General rights}

Copyright and moral rights for the publications made accessible in the public portal are retained by the authors and/or other copyright owners and it is a condition of accessing publications that users recognise and abide by the legal requirements associated with these rights.

- Users may download and print one copy of any publication from the public portal for the purpose of private study or research.

- You may not further distribute the material or use it for any profit-making activity or commercial gain

- You may freely distribute the URL identifying the publication in the public portal 


\section{Effect of Ammonia Addition on Microstructure and Wear Performance of Carbonitrided High Carbon Bearing Steel AISI 52100}

\section{Bin Liu' ${ }^{1}$, Bo Wang ${ }^{1,2}$, Jianfeng Gu ${ }^{1,3}$ *}

1. Institute of Materials Modification and Modelling, School of Materials Science and Engineering, Shanghai Jiao Tong University, Shanghai 200240, China

2. Department of Mechanical Engineering, Technical University of Denmark, Kongens Lyngby 2800, Denmark

3. Shanghai Key Laboratory of Materials Laser Processing and Modification, Shanghai Jiao Tong University, Shanghai 200240, China

Abstract: The investigation on the microstructure and tribomechanical behavior of hypereutectoid bearing steel AISI 52100 has been carried out during an unconventional thermo-chemical process aiming to improve the wear performance under dry conditions. The effects of $\mathrm{NH}_{3}$ addition rate on microstructure, hardness and wear performance of the carbonitrided specimen were characterized and the results show that two types of nitride $\left(\mathrm{CrN},(\mathrm{Cr}, \mathrm{Fe})_{2} \mathrm{~N}_{1-\mathrm{x}}\right)$ are formed in the surface layer. The quantity of the nitride and carbide precipitates increase firstly and decrease subsequently with the increasing of $\mathrm{NH}_{3}$ addition rate, whereas the fraction of retained austenite increases monotonically. The wear performance of the carbonitrided specimen is improved during the entire stage of the sliding test with the $\mathrm{NH}_{3}$ addition rate below $0.4 \mathrm{l} / \mathrm{min}$, but it decreases sharply at the initial stage of sliding test and then increases gradually when further raising the $\mathrm{NH}_{3}$ addition rate. The possible reasons underlying have been discussed and are attributed to the fraction of retained austenite formed during carbonitriding process and the transformation from retained austenite into martensite during sliding test, respectively.

Keyword: Hypereutectoid bearing steel; Carbonitriding; Ammonia addition rate; Retained austenite; Wear resistance

\footnotetext{
* Corresponding author. Tel.: +86 021 34203743; fax: +81 02134203742

E-mail address: gujf@sjtu.edu.cn (J. Gu).
} 


\section{Introduction}

Bearings are precision parts with which to sustain comprehensive performance for life endurance while operating under extra-high-speed and extra-heavy-duty conditions. Numerous tribologists have explored many innovative techniques to fulfill the ever-increasing bearing service demands ${ }^{[1-7]}$. It has been confirmed that the service life of the bearings is severely limited by the deterioration of the surface topography due to wear, which is defined as the mechanism of material removal or transfer caused by relative sliding between frictional body pairs ${ }^{[8]}$. Since the surface characteristics of the material have a great influence on wear ability [6-13], creating multicomponent and composite hard surface layers with excellent wear, corrosion and oxidation resistance makes it possible to obtain bearings with long service life.

Carbonitriding process is commonly conducted on low carbon steel to enhance surface hardness, wear, and fatigue characteristics through the formation of carbonitrided layer. Tribological properties of carbonitrided low carbon steel AISI 1020 was improved greatly and the hardness increased from 720 to $940 \mathrm{HV}{ }^{[14]}$. Metallurgical and mechanical responses of alloys $16 \mathrm{NiCrMo13}$ and 23MnCrMo5 to carbonitriding with the addition of carbon and/or nitrogen were investigated, which shows that less significant hardness drop was obtained in carbonitrided low-carbon-steel specimen after tempering as compared to the carburized one due to the secondary precipitation mechanism ${ }^{[15]}$. The effects of ammonia flow rate on the microstructure, distortion, hardness and strength have been investigated, but still focused on the low carbon steel ${ }^{[16]}$. Abrasion with shallow and narrower wear track was the predominant wear mechanism of carbonitrided AISI 8620 at $50 \mathrm{~N}$; whereas, high friction sliding 
mechanism at $150 \mathrm{~N}$ was controlled by plastic deformation ${ }^{[17]}$. However, the microstructure evolution on high carbon chromium bearing steel during carbonitriding and the friction behavior of carbonitrided specimens are extremely meager and uncomprehensive. J. Osés et al. ${ }^{[18]}$ studied the new duplex treatments on 100Cr6 bearing steel, mainly concerned on the properties of the surface through combining carbonitriding treatments, laser shock peening and physical vapor deposition. The carbonitriding process, which involves the diffusion of carbon and nitrogen into the steel, is considered to react to precipitations and generate stable retained austenite (RA) ${ }^{[19]}$. It has been proved that the fine precipitations and moderate RA have positive effects on enhancing fatigue performance and wear resistance ${ }^{[20-22]}$. Among the carbonitriding process parameters, the ammonia $\left(\mathrm{NH}_{3}\right)$ addition, which imparts varied nitrogen concentration in surface volume, is deemed to be one of the critical factors affecting the properties of surface layer ${ }^{[23-24]}$.

The objective of this work is to perform varied thermochemical carbonitriding processes on hypereutectoid steel AISI 52100 and to investigate the effects of $\mathrm{NH}_{3}$ addition rate on the microstructure, wear performance of the modified layer. The mechanism underlying has also been discussed.

\section{Experiment Procedure}

\subsection{Materials and Heat Treatment}

Specimens with a hardness of $200 \mathrm{HV}$ cut from the as-spherodized AISI 52100 bearing steel bars were ground up to a roughness of Ra 0.4 prior to carbonitriding. The chemical composition of the specimen 
as given in Table 1 was determined using Inductive Coupled Plasma Emission Spectrometer- JY2000 and carbon sulfur analyzer - LECO CS230. Carbonitriding processes were carried out at $835^{\circ} \mathrm{C}$ for 210 minutes in controlled atmosphere, which contains endogas with a fixed carbon potential of $1.0 \%$ and varied $\mathrm{NH}_{3}$ flowing rates from 0.28 to $1.2 \mathrm{l} / \mathrm{min}$. Subsequently, the carbonitrided specimens were quenched in oil at $80{ }^{\circ} \mathrm{C}$. The conventional quenching and tempering $(\mathrm{Q} / \mathrm{T})$ process was simultaneously performed for comparison.

\subsection{Material Characterization}

The treated specimens were cross-sectioned, ground, polished and etched with $4 \%$ nital etchant before observation. The cross-section of the specimens was protected using aluminum foil during the metallographic preparation to obtain reliable microstructure. Microstructure characterization was then carried out through optical microscope (OM) and TESCAN LYRA3 scanning electron microscopy (SEM). In-depth identification of precipitates formed during enrichment was performed through JEOL 2100F transmission electron microscope (TEM) and selected area electron diffraction patterns (SAED) by cutting out lamellae using TESCAN LYRA3 dual beam field emission SEM/FIB. The hardness profiles were determined using a micro hardness tester with a load of $0.3 \mathrm{~kg}$ and dwelling time of 10 seconds and, the hardness measurements were conducted along the profile of the sectioned samples. Phase analysis of the sample surface was conducted on a D/MAX-PC 2500 X-ray diffractometer (XRD) with scanning range $30 \sim 95^{\circ}$ and at a speed of $0.5^{\circ}$ per minute, and prior to conducting the XRD spectra, a thin layer (about 10 20 $\mathrm{m}$ ) had been removed from the surface through electrolytic etching device. The amount of RA before and after wear tests were measured by X-ray stress analyzer 
XSTRESS-3000-G3 ${ }^{+}$using four-diffraction-peak method $(\alpha(211), \gamma(220), \alpha(200), \gamma(200))$. The measurements were performed step by step by removing a thin layer $(100 \sim 150 \mu \mathrm{m})$ using an electrolytic etching device aiming to obtain reliable volume of RA.

\subsection{Wear Tests}

The wear tests were implemented on a wear tester with pin-on-disc configuration under dry conditions, as shown in Fig. 1. The treated specimens (pin) were revolved in an anti-clockwise motion at $500 \mathrm{rpm}$ in contact with the GCr15 steel disc at a load of $200 \mathrm{~N}$ for varied durations, which were selected as 5, 15, 25, 35, 45, 55, 65 minutes corresponding to sliding distances of 250, 750, 1250, 1750, 2250, 2750, 3250 meters respectively. The worn surfaces were subsequently characterized for friction behavior through SEM. Weight loss rates were also determined as a function of sliding distance using an accurate to $0.1 \mathrm{mg}$ microbalance.

\section{Results}

\subsection{X-ray Diffraction Analysis}

Fig. 2 presents the X-ray diffraction profiles of the surface layer experienced with carbonitrided treating at $\mathrm{NH}_{3}$ addition rates ranging from $0.28 \sim 1.2 \mathrm{l} / \mathrm{min}$ and $\mathrm{Q} / \mathrm{T}$ treating. The diffraction patterns in the surface of the $\mathrm{Q} / \mathrm{T}$ treated specimen contains predominantly martensite $\left(\alpha^{\prime}\right)$, and a few amount of RA $\left(\gamma^{\prime}\right)$ and $(\mathrm{Fe}, \mathrm{Cr})_{3} \mathrm{C}$ phases. The continuous formation of the $(\mathrm{Cr}, \mathrm{Fe})_{2} \mathrm{~N}_{1-\mathrm{x}}$ nitrides could be detected as the $\mathrm{NH}_{3}$ addition rate increasing from $0.28 \sim 1.2 \mathrm{l} / \mathrm{min}$. Relatively high and low $\mathrm{NH}_{3}$ addition rates are not conductive to the formation of $\mathrm{CrN}$, which are only detected in the $\mathrm{NH}_{3}$ addition rate in the range of $0.4 \sim 0.8 \mathrm{l} / \mathrm{min}$. 


\subsection{Microstructure in the surface layer}

Figs. 3a f show the surface layer metallurgical structures of the cross-section for the specimens which were subjected to $\mathrm{Q} / \mathrm{T}$ and carbonitriding treatment, respectively. The $\mathrm{Q} / \mathrm{T}$ treated specimen (Fig 3a) consists of a typical microstructure for bearing steel with martensite matrix, fine dispersed carbide particles $(\mathrm{Fe}, \mathrm{Cr})_{3} \mathrm{C}$ and minute amount of $\mathrm{RA}(\sim 7 \%)$. Clearly, no white layer consisting of carbonitrides or nitrides is formed in the surface of the treated specimen without $\mathrm{NH}_{3}$. Adding $\mathrm{NH}_{3}$ as the nitrogen carrier in the carbon atmosphere causes the accelerated precipitation of nitrides and larger amount of retained austenite, as can be seen from Figs. 3 b-f.

The cross-section microstructure (marked with dotted line in Fig. 3c) of the specimen treated at an $\mathrm{NH}_{3}$ addition rate of $0.4 \mathrm{l} / \mathrm{min}$ was further resolved by SEM, as shown in Fig. 4a. Obviously, the modified layer was characterized by the cryptocrystalline martensite, blocky RA, and clusters of precipitates with an average size of $1.2 \mu \mathrm{m}$. EDS results (Fig. 4b) verified that the composition of the particle (as marked with a circle in Fig. 4a) predominantly contains chromium (Cr), nitrogen (N) and iron (Fe) elements. This is in consistent with the XRD analysis results that the nitrides are speculated as $(\mathrm{Cr}, \mathrm{Fe})_{2} \mathrm{~N}_{1-\mathrm{x}}$ and/or CrN. Furthermore, lamella was extracted from the subsurface (about $50 \mu \mathrm{m}$ from the surface) layer using a focused ion beam (FIB) machining, as marked rectangular region line in Fig. 4a. The detailed microstructure information of the lamella reflected by the TEM bright/dark field images and the corresponding selected area electron diffraction (SAED) patterns are shown in Fig.4c f. 


\subsection{Hardness and effective modified layer}

Fig. 5 shows the microhardness profiles of carbonitriding and Q/T treating specimens. As plotted in the figure, the microhardness with an average value of $748 \mathrm{HV}_{0.3}$ is normally constant with depth for $\mathrm{Q} / \mathrm{T}$ treating specimen. However, large variations of microhardness as a function of depth for specimens with $\mathrm{NH}_{3}$ addition rates are revealed. Furthermore, the near-surface hardness of the carbonitrided specimen is increased to peak value at the $\mathrm{NH}_{3}$ addition rate of $0.40 \mathrm{l} / \mathrm{min}$, and subsequently decreased with further increasing the $\mathrm{NH}_{3}$ addition rate.

\subsection{Friction and wear behavior}

The wear weight loss rates of the specimen carbonitrided with different $\mathrm{NH}_{3}$ addition rates ranging from $0.28 \mathrm{l} / \mathrm{min}$ to $1.20 \mathrm{l} / \mathrm{min}$ as a function of sliding distance are shown in Fig. 6 . The figure shows that the $\mathrm{Q} / \mathrm{T}$ treated specimen has the largest weight loss rate, while specimen treated with $0.40 \mathrm{l} / \mathrm{min}$ has the smallest weight loss rate. The weight loss rates are decreased gradually as the specimen treated with $\mathrm{NH}_{3}$ addition rate over $0.6 \mathrm{l} / \mathrm{min}$ at the first stage of sliding distance less than $1200 \mathrm{~m}$. Subsequently, the weight loss rates of all specimens are increased progressively. Fig. 7 shows the weight loss rate decreases rapidly to the bottom at $\mathrm{NH}_{3}$ addition rate of $0.4 \mathrm{l} / \mathrm{min}$ and subsequently increases gradually at initial sliding distance of $280 \mathrm{~m}$.

Fig. 8 and Fig.9 show the typical worn surfaces of the carbonitriding treated specimens with varied $\mathrm{NH}_{3}$ addition rates at sliding distance of $280 \mathrm{~m}$ and $3200 \mathrm{~m}$, respectively. Fig.8a shows the 
morphology of the obvious abrasion grooves for $\mathrm{Q} / \mathrm{T}$ treated specimen at the initial wear testing stage. Figs.8b-f indicates the features of wide, continuous abrasion grooves, flakes, and plastic deformation as well for carbonitrided specimens. Observations from Figs.9 b-f reveal that wider and smoother wear scars have formed on carbonitrided specimens, in contrast that plenty of flakes are presented on the worn surface of Q/T treated specimens (Fig.9 a).

\section{Discussion}

\subsection{Effects of $\mathrm{NH}_{3}$ Addition Rate on Microstructure}

Adding $\mathrm{NH}_{3}$ in the gas medium directly caused the formation of different nitrides, the XRD and EDS analysis results roughly substantiate that $(\mathrm{Cr}, \mathrm{Fe})_{2} \mathrm{~N}_{1-\mathrm{x}}$, and $\mathrm{CrN}$ nitrides are precipitated at the surface layer. TEM results show that both tetragonal-shaped and long striped precipitates are observed in the selected region, the dark field images and corresponding selected area electron diffraction patterns in Fig. 4d and Fig. 4f further confirm the $(\mathrm{Cr}, \mathrm{Fe}){ }_{2} \mathrm{~N}_{1-\mathrm{x}}$ and $\mathrm{CrN}$ nitrides respectively.

According to the XRD patterns, $(\mathrm{Cr}, \mathrm{Fe})_{2} \mathrm{~N}_{1-\mathrm{x}}$, and $\mathrm{CrN}$ nitrides are formed at a critical $\mathrm{NH}_{3}$ addition rate of over $0.28 \mathrm{l} / \mathrm{min}$ due to the fact that sufficient nitrogen atoms are introduced into the substrate. However, CrN nitrides are disappeared at the rate of over $0.8 \mathrm{l} / \mathrm{min}$, probably due to the higher nitrogen solubility caused by the interaction of interstitial carbon and nitrogen ${ }^{[23]}$. With increasing the $\mathrm{NH}_{3}$ addition rates from 0.28 to $1.2 \mathrm{l} / \mathrm{min}$, the amount of precipitated tetragonal-shaped particles is increased firstly and reached to the maximum volume fraction at $0.40 \mathrm{l} / \mathrm{min}$, and then decreased gradually (Figs.3 b-f). It should be noted that the reacted phases of $(\mathrm{Cr}, \mathrm{Fe}){ }_{2} \mathrm{~N}_{1-\mathrm{x}}$, and $\mathrm{CrN}$ nitrides 
impart the surface layer superior wear ability ${ }^{[6]}$.

However, the fraction of retained austenite is increased continuously with the increasing of $\mathrm{NH}_{3}$ addition rate. The maximum amount of RA before wear tests is up to $35.8 \%$ at the $\mathrm{NH}_{3}$ addition rate of $1.20 \mathrm{l} / \mathrm{min}$, as show in Fig 10. The evolution of nitrides and the volume of RA for differently treated specimens can be illustrated as follows: The effects of nitrogen diffusion into the surface are, on the one hand, that it dissolves in the matrix and forms interstitial solid solution, expands the austenite phase field, and stabilizes the RA. On the other hand, the precipitates of nitride can be nucleated at the supersaturation grain boundaries and growth gradually ${ }^{[25]}$. It is considered that the formation of RA and nitrides is affected greatly by the simultaneous and competitive introducing of carbon and nitrogen during the process.

\subsection{Effects of $\mathrm{NH}_{3}$ Addition Rate on hardness and Wear Properties}

The fine precipitates of nitride and aggregated carbides in the fine martensitic matrix support the positive impact on enhancing the surface hardness of carbonitrided specimens, as compared to the Q/T treated specimen. However, it shows that as the $\mathrm{NH}_{3}$ addition rate is up to $1.20 \mathrm{l} / \mathrm{min}$, the surface hardness decreases sharply to $756 \mathrm{HV}_{0.3}$. This is possibly attributed to the larger amount of RA ( 35.8\%) and less volume of carbides and/or nitrides (about 8.5\%) as shown in Fig.10 and Table 2. On the one hand, the interstitial nitrogen strongly stabilizes the austenite, which possesses lower hardness. And on the other hand, the solution nitrogen atoms induce to create carbides/nitrides, which can elevate the hardness. The hardness of the carbonitrided layer is the comprehensive effect of the nitric 
martensite, retained austenite and the precipitations.

All the carbonitrided specimens have lower weight loss rates as compared to the $\mathrm{Q} / \mathrm{T}$ treated specimens during the entire wear testing. These indicate that carbonitriding process has positive effect on the wear performance. The wear test results also clearly show that, the specimen treated with a 0.4 1/min $\mathrm{NH}_{3}$ addition rate has the lowest weight loss rate, which indicates the most outstanding wear resistance. This proved the fact that numerous fine carbides/nitrides and appropriate RA in the carbonitrided layer can strongly prevent friction and the micro crack initiation during the entire testing period.

It also should be noted from Fig.7 that, at the initial stage of sliding ( $280 \mathrm{~m})$, the weight loss rates of carbonitrided specimens decrease gradually with the increasing of $\mathrm{NH}_{3}$ addition rate up to $0.4 \mathrm{l} / \mathrm{min}$, and then the weight loss rates increase slowly. This indicates that the initial wear performance of the specimen is improved continuously by carbonitriding up to the $\mathrm{NH}_{3}$ addition rate of $0.4 \mathrm{l} / \mathrm{min}$. It is known that, the influences of nitrogen atoms penetrating into the matrix can be divided into two parts, solid solution in substrate and precipitation to nitrides ${ }^{[24,25]}$. The ultimate effect of wear performance is the competitive result of the interaction between the fine carbides/nitrides and RA. It clearly indicates that the nitrides/carbides are the dominant factor to wear performance when the $\mathrm{NH}_{3}$ addition rate is below $0.40 \mathrm{l} / \mathrm{min}$, which has a maximum volume of nitrides/carbides and moderate fraction of RA (18\%). However, it transforms to wear controlled by the RA as the $\mathrm{NH}_{3}$ addition rate over $0.40 \mathrm{l} / \mathrm{min}$. Specimens treated with $1.20 \mathrm{l} / \mathrm{min} \mathrm{NH}_{3}$ addition rate, which has the largest amount of 
RA (35.8\%), have the highest level of weight loss rates at the initial testing stage of $280 \mathrm{~m}$, clearly evidenced that the dominant factor of wear performance is controlled by RA at this stage. However, with the sliding test continuing (at the sliding distance of $3200 \mathrm{~m}$, as depicted in Fig. 7), the wear performance of specimens treated with the $\mathrm{NH}_{3}$ addition rate over $0.6 \mathrm{l} / \mathrm{min}$ is increased gradually probably attributed to the more fraction of RA transforming to martensite. However, it should be noted that an appropriate volume of RA can favor the contact fatigue performance under contaminated conditions [26], although it is detrimental to the wear performance in the initial stage of the wear test.

\subsection{Effects of $\mathrm{NH}_{3}$ Addition Rate on Wear Mechanism}

The morphology of the obvious abrasion grooves in Fig. 8a indicates that adhesive wear along with oxidation is the predominant wear mechanism for the $\mathrm{Q} / \mathrm{T}$ treated sample. The worn surface, which characterized by wide, continuous abrasion grooves, flakes, and plastic deformation as well in Figs. 9b-f, demonstrates that the wear regime is transited from adhesive wear to abrasive wear. It is known that the microstructure of the carbonitrided specimens contains nitric martensite, fine carbides/nitrides and larger volume of RA content ( $\approx 18.5 \% \sim 35.8 \%)$. The regime changing is so because that, on the one hand, the larger amount of austenite introduced by carbonitriding process can be easily deformed and the RA transformation to martensite leads to local residual compressive stress and higher hardness during sliding. On the other hand, the generated carbides/nitrides in the surface layer are probably detached as continually sliding test and formed to three-body friction, and the fine detached precipitates of carbides/nitrides actually act as a role of solid lubricants. The surfaces of Q/T treated specimens are delaminated as dices during initial stage due to the elevated temperature resulting from 
sliding. However, micro plastic deformation and grooves on the worn surfaces created by three-body friction are observed on the surface of carbonitrided specimens, it's the evidence that the wear performance is improved by the transformation of RA and precipitates of nitride.

At the second stage of wear testing, observations from Figs.9 b-f reveal that wider and smoother, but small number of wear scars are formed on carbonitrided specimens, in contrast that plenty of flakes are presented on the worn surface of Q/T treated specimens (Fig.9 a). It's also the evidence that carbonitriding process allows for better deformability in surface layers during sliding tests, indicating that the carbonitriding favors for improving wear resistance for the overall sliding distance probably attributed to the higher hardness resulting from strain-induced transformation of RA to martensite and fine carbides/nitrides. 


\section{Conclusions}

The microstructure and wear performance of hypereutectoid bearing steel AISI 52100, subjected to carbonitriding process with varied $\mathrm{NH}_{3}$ addition rates, have been characterized and tested, respectively, and the following conclusions can be summarized.

1. Two types of nitrides $\left(\mathrm{CrN},(\mathrm{Cr}, \mathrm{Fe})_{2} \mathrm{~N}_{1-\mathrm{x}}\right)$ are observed in the surface layer of carbonitrided specimens. The quantity of nitrides increases to a maximum level with the $\mathrm{NH}_{3}$ addition rate of 0.4 1/min, and then decreases gradually with further raising of the $\mathrm{NH}_{3}$ addition rate. No CrN nitride is formed when the $\mathrm{NH}_{3}$ addition rate is over $0.8 \mathrm{l} / \mathrm{min}$. The volume fraction of RA increases almost linearly from $18.5 \%$ to $35.8 \%$ when $\mathrm{NH}_{3}$ addition rate is correspondingly set from $0.28 \mathrm{l} / \mathrm{min}$ to 1.20 l/min during the carbonitriding process.

2. The surface hardness of carbonitrided specimens increases primarily due to the precipitation of nitrides, causing the better wear performance comparing to $\mathrm{Q} / \mathrm{T}$ treated specimens. The specimen treated with the $\mathrm{NH}_{3}$ addition rate of $0.4 \mathrm{l} / \mathrm{min}$ has the most outstanding wear performance as compared to other specimens due to the maximum quantity of carbides/nitrides and appropriate fraction of RA.

3. The microstructures in carbonitrided layer, i.e., the quantity of carbides/nitrides and fraction of RA play an important role in wear performance, and the wear performance is also related to the sliding distance of wear test. 
When the increasing of $\mathrm{NH}_{3}$ addition rate is lower than $0.4 \mathrm{l} / \mathrm{min}$, the wear performance increases with the increasing of $\mathrm{NH}_{3}$ addition rate, because the increasing of carbides/nitrides quantity plays the dominant effect instead of increasing of RA fraction.

When the increasing of $\mathrm{NH}_{3}$ addition rate is higher than $0.4 \mathrm{l} / \mathrm{min}$, the wear performance at the initial stage (with the sliding distance less than $280 \mathrm{~m}$ ) decreases with the increasing of $\mathrm{NH}_{3}$ addition rate due to the dominant effect from the increasing of RA fraction. Whereas the wear performance is improved gradually at the second stage (with the sliding distance about $3200 \mathrm{~m}$ ), and the possible reason may be attributed to the strain-induced transformation of RA to martensite.

\section{Acknowledgments}

This work was financially supported by the National Natural Science Foundation of China (Grant No. 51701122) and Baotou-SJTU Innovation Guidance (No. 18H100000174). 


\section{References}

[1] H.K.D.H. Bhadeshia, Steels for bearings, Prog. Mater Sci. 57 (2012) 268-435.

[2] J.Y. Li, D. Ye, C. Bai, J.T. He, G.W. Wang, W. Yang, Investigations on femtosecond laser modified micro-textured surface with anti-friction property on bearing steel GCr15, Appl. Surf. Sci. 434 (2018) 831- 842.

[3] A. Buling, H. Sändker, J. Stollenwerk, U. Krupp, A. H. Steinmeier, Laser surface pretreatment of 100Cr6 bearing steel - Hardening effects and white etching zones, Appl. Surf. Sci. 378 (2016) 564- 571.

[4] S. Roy, S. Sundararajan, The effect of heat treatment routes on the retained austenite and tribomechanical properties of carburized AISI 8620 steel, Surf. \& Coat. Technol. 308 (2016) 236-243.

[5] Y.X. Lao, H. Du, T.Y. Xiong, Y. Wang, Evolution behaviors of oxides in severely plastic deformed region of AISI 52100 steel during dry sliding wear, J. Mater. Sci. Technol. 33 (2017) 330-337.

[6] K. Kobs, H. Dimigen, C.J.M. Gerritsen, E. Gerritsen, J. Politiek, L. J. van Ijzendoorn, R. Oechsner, A. Kluge, H. Ryssel, Friction reduction and zero wear for 52100 bearing steel by high-dose implantation of carbon, Appl. Phys. Lett. (1990) 1622-1624.

[7] F. Sadeghi, B. Jalalahmadi, T. S. Slack, N. Raje, N. K. Arakere, A review of rolling contact fatigue, J. Tribol. 131 (2009) 041403-1-15.

[8] A. V. Olver, The mechanism of rolling contact fatigue: an update, J. Eng. 219 (2005) 313-330.

[9] K. Tsubota, T. Sato, Y. Kato, K. Hiraoka, R. Hayashi, Bearing steels in the 21st century bearing steels: into the 21st century, Proc. Conf. ASTM STP. 1327 (1998) 202-215.

[10]J.M. Beswick, Fracture and fatigue crack propagation properties of hardened 52100 steel, Metall. Mater. Trans. A 20 (1989) 1961-1973.

[11]K. Monma, R. Maruta, T. Yamamoto, Y. Wakikado, Effect of particle sizes of carbides and amounts of undissolved carbide on the fatigue life of bearing steel, J. Jpn. Inst. Met. 32 (1968) 1198-1204.

[12]G.E. Hollox, R.A. Hobbs, J.M. Hampshire, Lower bainite bearings for adverse environments, Wear 68 (1981) 229-240.

[13]J.A. Eckel, P.C. Glawas, J.O. Wolfe, B.J. Zorc, Clean engineered steels - progress at the end of the 20th century. In: Mahaney Jr JK, editor. Advances in the production and use of steel with improved internal cleanliness, Pennsylvania (USA): ASTM (1999) 1-10.

[14] M.B. Karamis, D. Odabas, A simple approach to calculation of the sliding wear coefficient for medium carbon steels, Wear 151 (1991)23-34. 
[15]W. Dal'Maz Silva, J. Dulcy, J. Ghanbaja, A. Redjaimia, G. Michel, S. Thibault, T. Belmonte, Carbonitriding of low alloy steels: Mechanical and metallurgical responses, Mater. Sci. Eng. A 693 (2017) 225-232.

[16]N. Taweejun, C. Kanchanomai, Effects of carbon and nitrogen on the microstructure and mechanical properties of carbonitrided low-carbon steel, J. Mater. Eng. Perform. 24 (2015) 4853-4862.

[17]R. Sankaran, D. Rajamani, S. Natarajan, K. G. Thirugnanasambantham, Sliding wear behaviour and its mechanisms of carbonitrided AISI 8620 steel at $100^{\circ} \mathrm{C}$ under unlubricated conditions, Surf. Eng. Vol 33 (2017) 42-45.

[18] J. Osés, G. G. Fuentes, S. Santo Domingo, I. Miguel, S. Gimeno, L. Carreras, P. Peyre, C. Gorny, Development of new duplex treatments on 100Cr6 steel combining Thermochemical Treatments, laser shock peening and physical vapour deposition, IOP Conf. Series: Journal of Physics: Conf. Series 843 (2017) 012080.

[19]Rajan, V. Joshi, A. Ghosh, Effect of carbonitriding on endurance life of ball bearing produced from SAE 52100 bearing steels, J. Surface Engineered Materials and Advanced Technology. 3 (2013), 172-177.

[20]C.M. Suh, M.H. Lee, Y.S. Pyoun, Fatigue characteristics of SKD-61 by ultrasonic nanocrystal surface modification technology under static load variation, Int. J. Mod. Phys. B 24 (2010) 2645-50.

[21]H.J. Böhmer, T.H. Hirsch, E. Streit, Rolling contact fatigue behavior of heat resistant bearing steels at high operational temperatures, Mat.-wiss. u. Werkstofftech 30(1999) 533-41.

[22]B.Wang, X.F. Zhao, W,Z. Li, M. Qin, J.F. Gu, Effect of nitrided-layer microstructure control on wear behavior of AISI H13 hot work die steel, Appl. Surf. Sci. 431(2018) 39-43.

[23] J. Slycke, T. Ericsson, A study of reactions occurring during the carbonitriding process, J. Heat Treating. 2 (1981) 1-17.

[24] M.L. Fares, A. Talhi, K. Chaoui1, M.Z. Touhami, Effects of gas carbonitriding process on surface characteristics of new hot working tool steel, Surf. Eng. 27 (2011) 595-601.

[25]A.R. Clauss, E. Bischoff, S.S. Hosmani, R.E. Schacherl, E.J. Mittemeijer, Crystal structure and morphology of mixed Cr1-xAlxN nitride precipitates: Gaseous nitriding of a Fe-1.5 Wt Pct Cr-1.5 Wt Pct Al alloy, Metall. and Mater. Trans. A 40A (2009) 1923-1934.

[26]Y. Shen, S.M. Moghadam, F. Sadeghi, K. Paulson, R.W. Trice, Effect of retained austenite Compressive residual stresses on rolling contact fatigue life of carburized AISI 8620 steel, Int. J. of Fatigue. 75 (2015) 135-144. 


\section{Figure captions}

Fig.1 The dimensions of specimen and the schematic configuration of the wear tester.

Fig.2 XRD patterns for surface layers of the carbonitrided specimens treated at $\mathrm{NH}_{3}$ addition rate ranging from $0.28 \sim 1.20 \mathrm{l} / \mathrm{min}$ and $\mathrm{Q} / \mathrm{T}$ treated specimen.

Fig. 3 Cross sectional microstructure of specimens treated at different $\mathrm{NH}_{3}$ addition rate (a) Q/T, (b) $0.28 \mathrm{l} / \mathrm{min}$, (c) $0.40 \mathrm{l} / \mathrm{min}$, (d) $0.60 \mathrm{l} / \mathrm{min}$, (e) $0.80 \mathrm{l} / \mathrm{min}$, (f) $1.20 \mathrm{l} / \mathrm{min}$. “R” denotes resin protective layer for Q/T specimen and “A” denotes aluminum protective layer in carbonitrided specimens, and red dotted line rectangle area is selected for in-depth resolution in Fig.4.

Fig. 4 SEM micrograph and EDS of the specimen surface layer treated with $\mathrm{NH}_{3}$ addition rate of 0.4 1/min: (a) SEM micrograph of rectangle in Figure 3c, (b) EDS of nitride marked in cycle (a), (c) TEM bright field image and (d) dark field image and corresponding SAED for (Cr, Fe) ${ }_{2} \mathrm{~N}_{1-\mathrm{x}}$, (e) TEM bright field image and, (f) dark field image and corresponding SAED for CrN.

Fig. 5 Micro hardness profiles of SAE 52100 specimens treated with different $\mathrm{NH}_{3}$ addition rate.

Fig. 6 Weight loss rate of specimens treated with different $\mathrm{NH}_{3}$ addition rate under loads of $200 \mathrm{~N}$ and speed of $500 \mathrm{rpm}$.

Fig 7 Variation of weight loss rates of specimens with different $\mathrm{NH}_{3}$ addition rate at sliding distance of $280 \mathrm{~m}$ and $3200 \mathrm{~m}$ under loads of $200 \mathrm{~N}$ and speed of $500 \mathrm{rpm}$.

Fig 8 The fraction of RA in carbonitrided and worn specimens treated with different NH3 addition rate.

Fig.9 SEM imagines of the worn surface at sliding distance of $280 \mathrm{~m}$ for the different $\mathrm{NH}_{3}$ addition rate (a) Q/T, (b) $0.28 \mathrm{l} / \mathrm{min}$, (c) $0.40 \mathrm{l} / \mathrm{min}$,(d) $0.60 \mathrm{l} / \mathrm{min}$, (e) $0.80 \mathrm{l} / \mathrm{min}$ and (f) $1.20 \mathrm{l} / \mathrm{min}$. 
Fig.10 SEM imagines of the worn surface at sliding distance of $3200 \mathrm{~m}$ for the different $\mathrm{NH}_{3}$ addition rate (a) Q/T, (b)0.28 l/min, (c) $0.40 \mathrm{l} / \mathrm{min}$, (d) $0.60 \mathrm{l} / \mathrm{min}$, (e) $0.80 \mathrm{l} / \mathrm{min}$ and (f) $1.20 \mathrm{l} / \mathrm{min}$. 
Table 1. Chemical compositions of tested specimen (wt \%)

\begin{tabular}{cccccccc}
\hline $\mathrm{C}$ & $\mathrm{Mn}$ & $\mathrm{Si}$ & $\mathrm{Cr}$ & $\mathrm{Ni}$ & $\mathrm{Mo}$ & $\mathrm{P}$ \\
\hline 0.981 & 0.314 & 0.213 & 1.582 & 0.013 & 0.015 & 0.011 & 0.005 \\
\hline
\end{tabular}

Table 2. Statistical results of quantitative measurements on the carbides/nitrides

\begin{tabular}{cccc}
\hline Sample & Mean diameter $/ \mu \mathrm{m}$ & Standard deviation / $\mu \mathrm{m}$ & Area fraction / \% \\
\hline $\mathrm{Q} / \mathrm{T}$ & 0.27 & 0.21 & $5.1 \%$ \\
$0.28 \mathrm{l} / \mathrm{min}$ & 0.38 & 0.19 & $7.1 \%$ \\
$0.40 \mathrm{l} / \mathrm{min}$ & 0.93 & 0.12 & $11.3 \%$ \\
$0.60 \mathrm{l} / \mathrm{min}$ & 0.78 & 0.13 & $10.6 \%$ \\
$0.80 \mathrm{l} / \mathrm{min}$ & 0.54 & 0.15 & $10.2 \%$ \\
$1.20 \mathrm{l} / \mathrm{min}$ & 0.42 & 0.15 & $8.5 \%$ \\
\hline
\end{tabular}





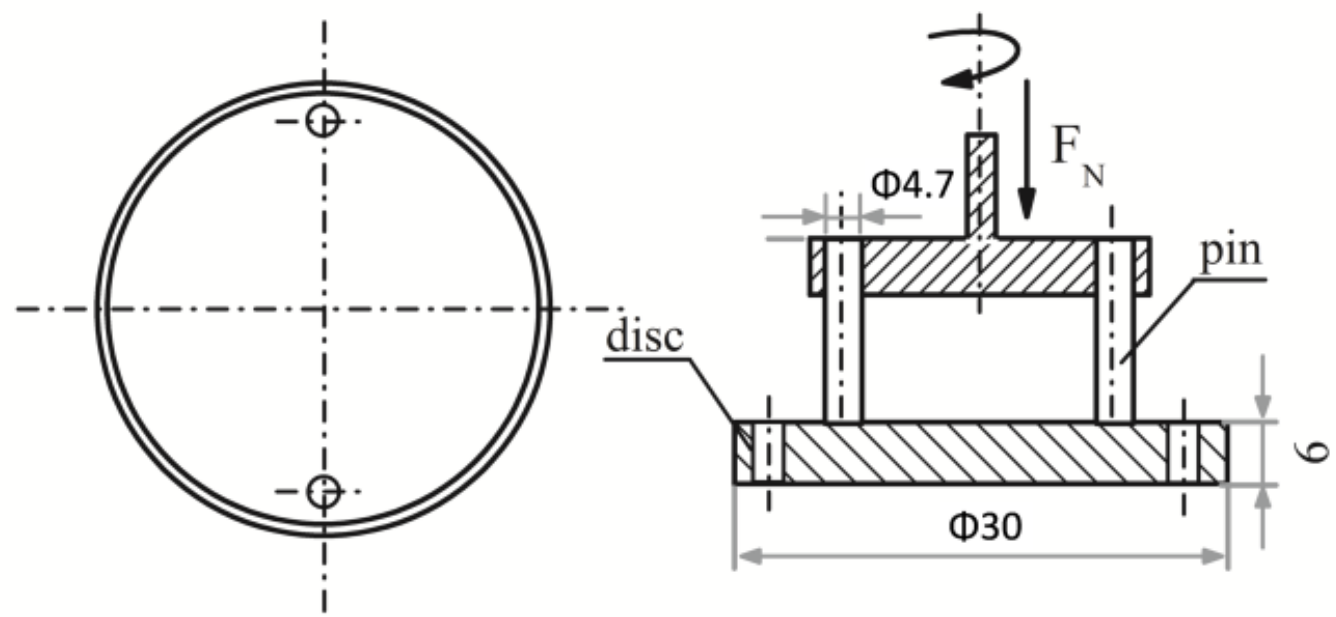

Fig.1 The dimensions of specimen and the schematic configuration of the wear tester.

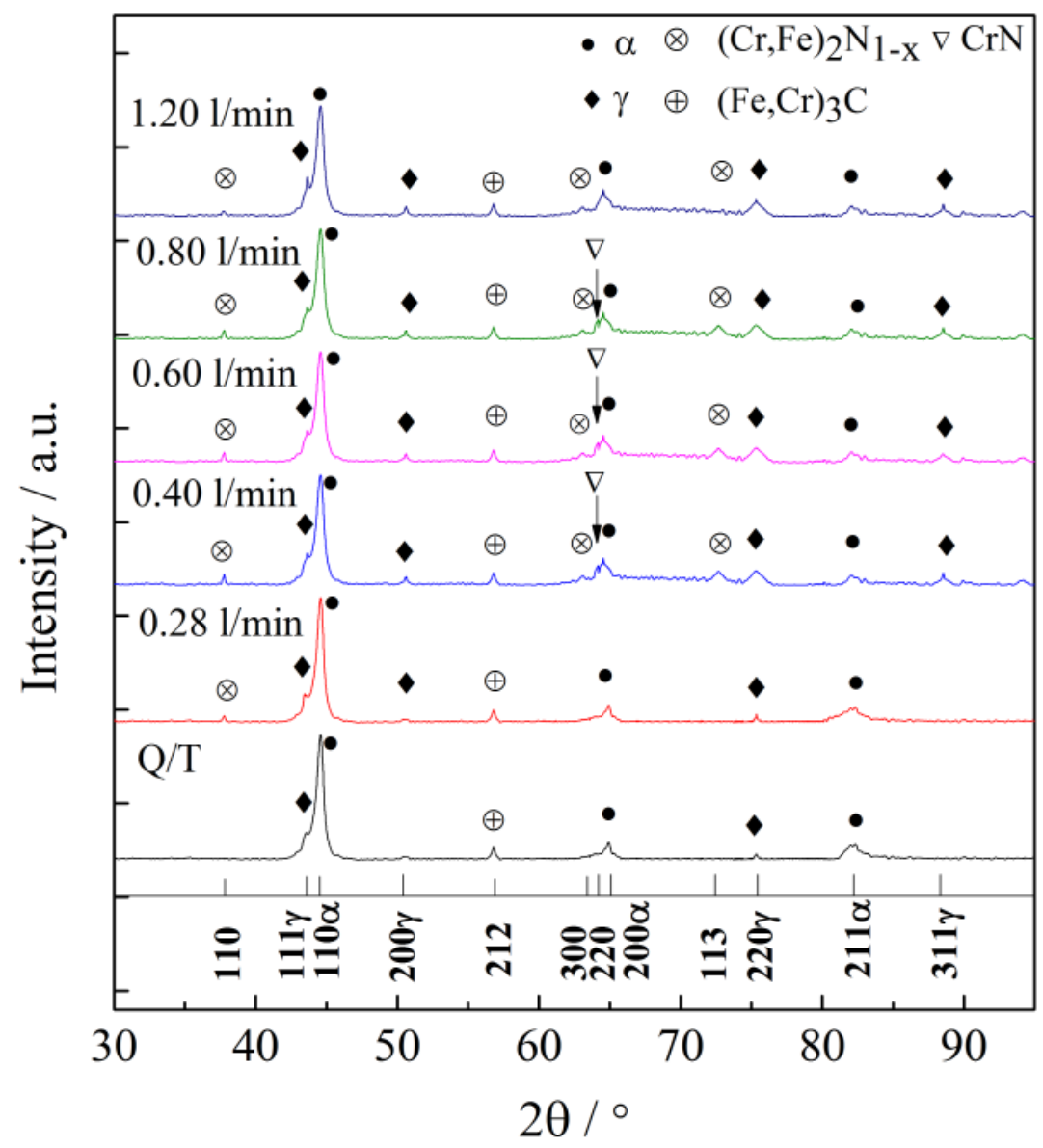

Fig.2 XRD patterns for surface layers of the carbonitrided specimens treated with $\mathrm{NH}_{3}$ addition rate ranging from $0.28 \sim 1.20 \mathrm{l} / \mathrm{min}$ and $\mathrm{Q} / \mathrm{T}$ treated specimen. 

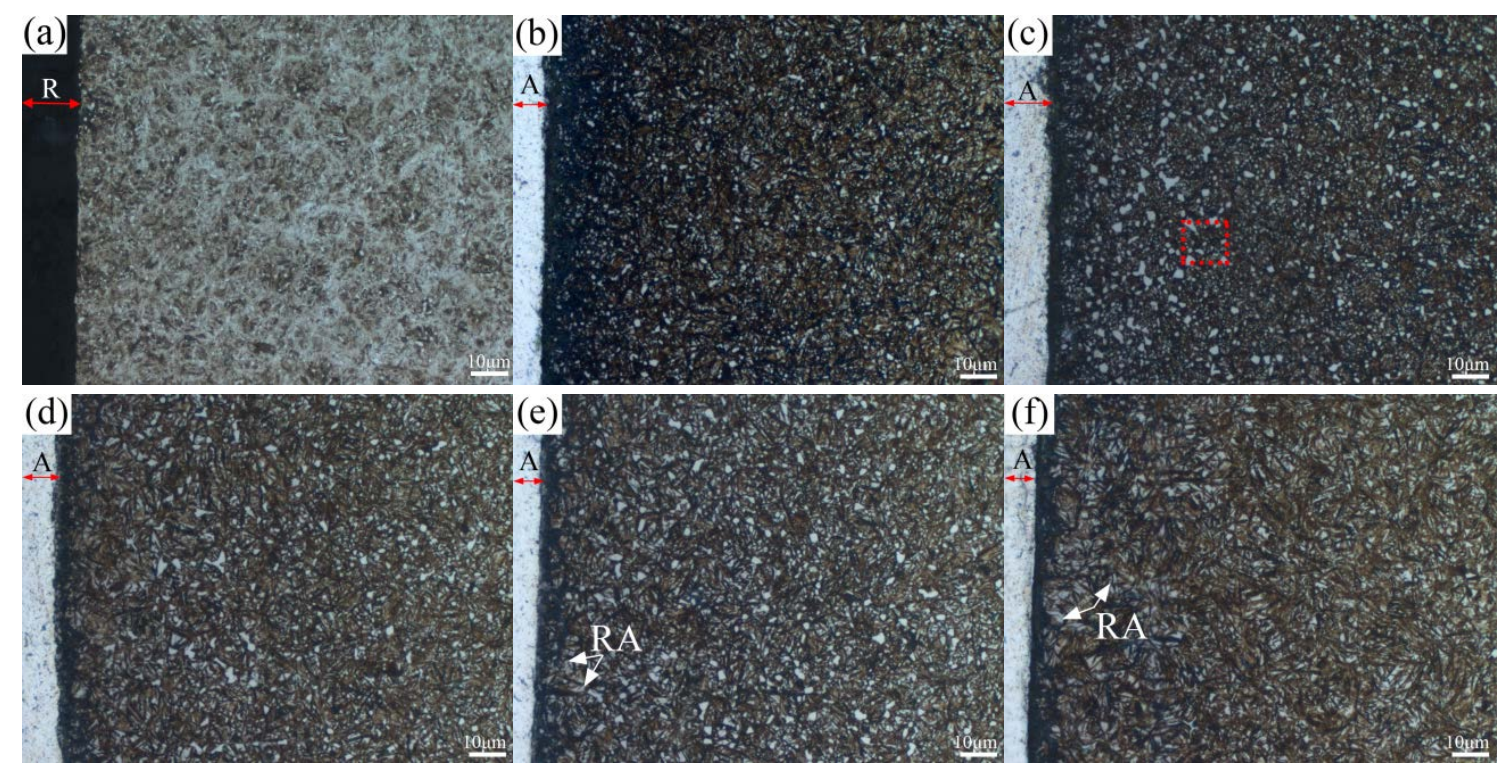

Fig. 3 Cross sectional microstructure of specimens treated with different $\mathrm{NH}_{3}$ addition rate (a) Q/T, (b) $0.28 \mathrm{l} / \mathrm{min}$, (c) $0.40 \mathrm{l} / \mathrm{min}$, (d) $0.60 \mathrm{l} / \mathrm{min}$, (e) $0.80 \mathrm{l} / \mathrm{min}$, (f) $1.20 \mathrm{l} / \mathrm{min}$. "R" denotes resin protective layer in Q/T specimen and “A” denotes aluminum protective layer in carbonitrided specimens, and red dotted line rectangle area is selected for in-depth resolution in Fig.4.
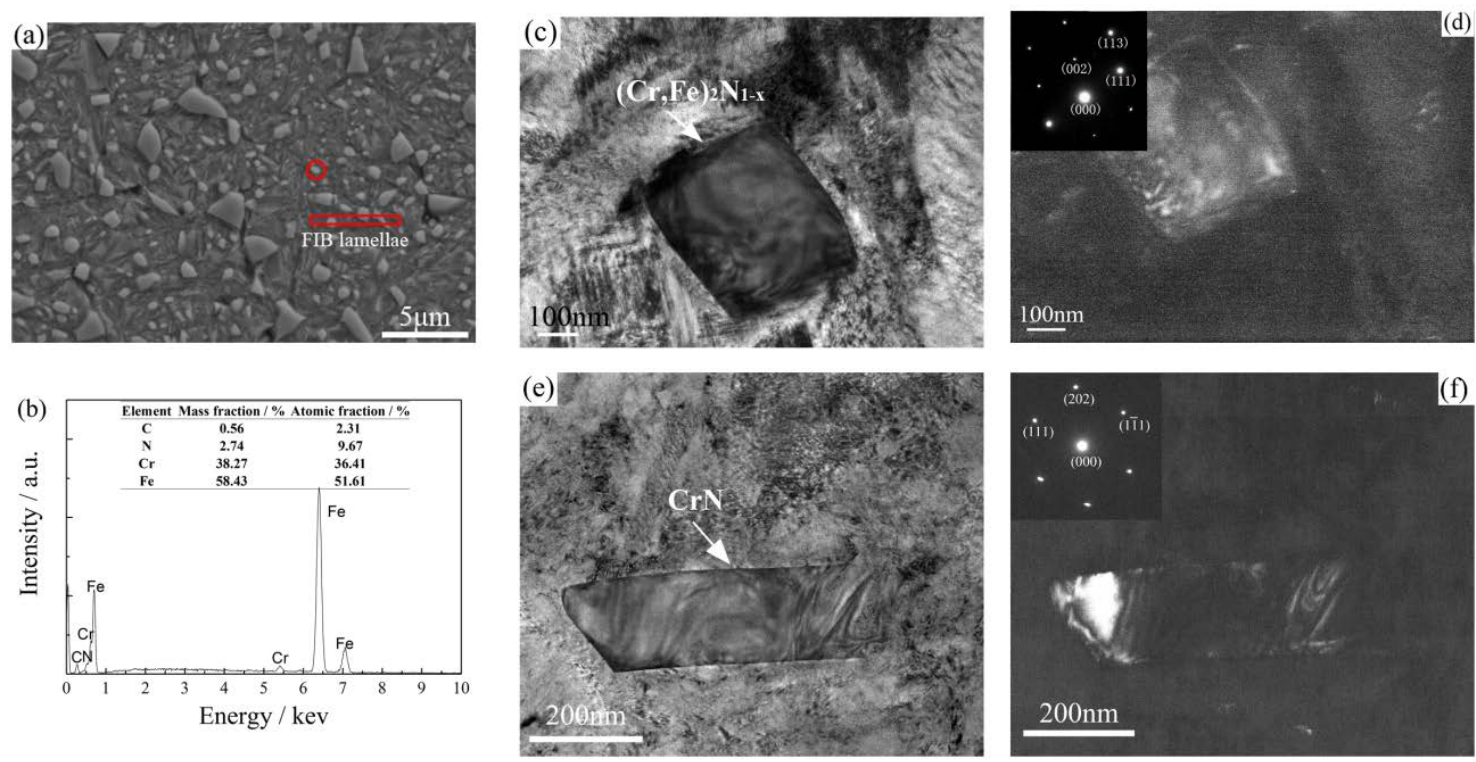

Fig. 4 SEM micrograph and EDS of the specimen surface layer treated with $\mathrm{NH}_{3}$ addition rate of 0.4 1/min: (a) SEM micrograph of rectangle in Figure 3c, (b) EDS of nitride marked in (a), (c) TEM bright field image and (d) dark field image and corresponding SAED for $(\mathrm{Cr}, \mathrm{Fe})_{2} \mathrm{~N}_{1-\mathrm{x}}$, (e) TEM bright field image and, (f) dark field image and corresponding SAED for CrN. 


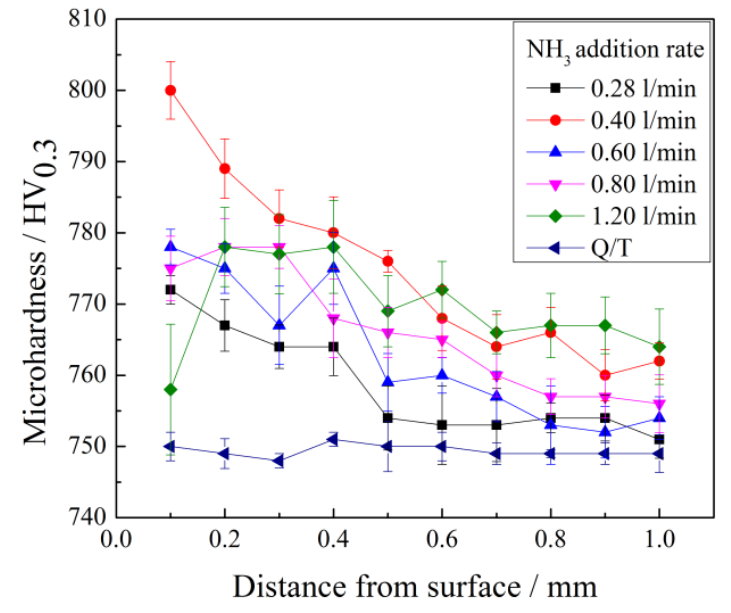

Fig. 5 Micro-hardness profiles of SAE 52100 specimens treated with different $\mathrm{NH}_{3}$ addition rate.

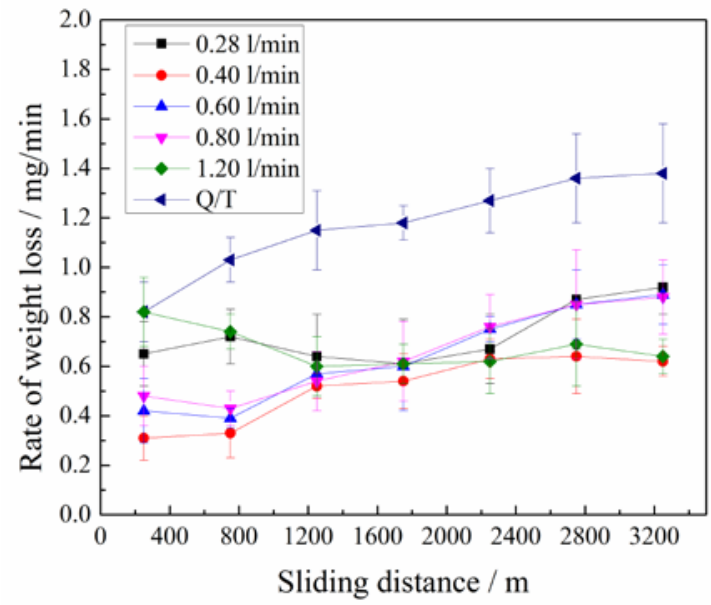

Fig. 6 Weight loss rate of specimens treated with different $\mathrm{NH}_{3}$ addition rate under loads of $200 \mathrm{~N}$ and speed of $500 \mathrm{rpm}$.

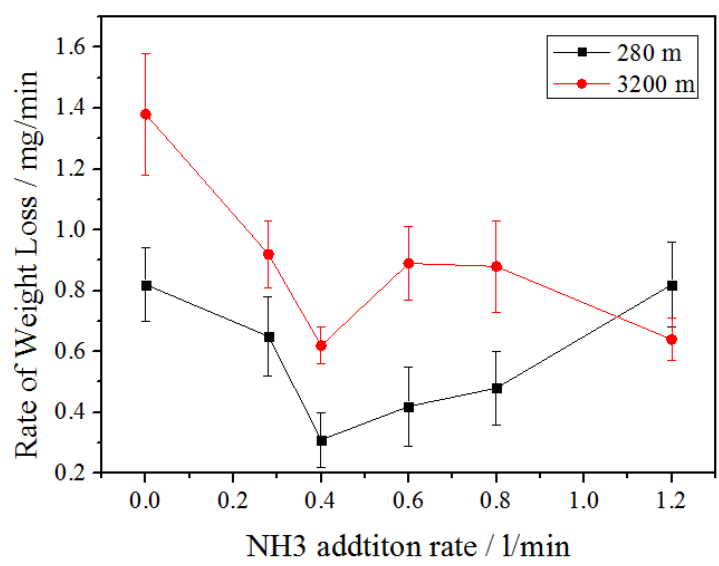

Fig. 7 Variation of weight loss rates of specimens with different $\mathrm{NH}_{3}$ addition rate at sliding distance of $280 \mathrm{~m}$ and $3200 \mathrm{~m}$ under loads of $200 \mathrm{~N}$ and speed of $500 \mathrm{rpm}$. 

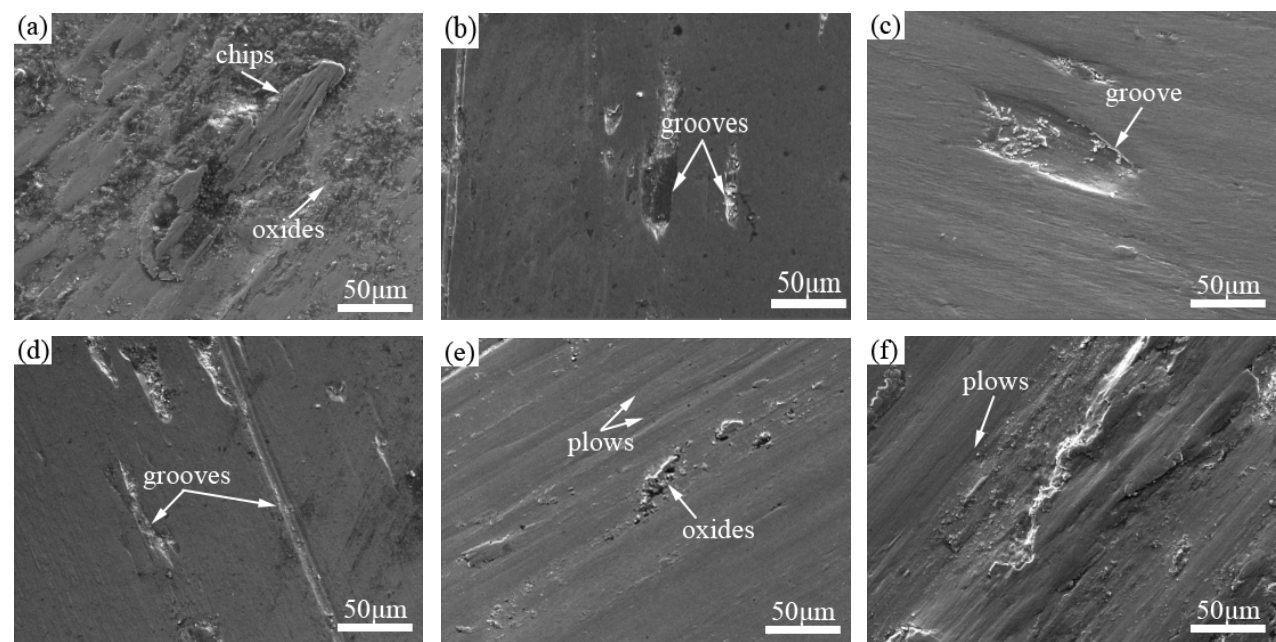

Fig.8 SEM imagines of the worn surface at sliding distance of $280 \mathrm{~m}$ for the different $\mathrm{NH}_{3}$ addition rate (a) Q/T, (b) $0.28 \mathrm{l} / \mathrm{min}$, (c) $0.40 \mathrm{l} / \mathrm{min}$,(d) $0.60 \mathrm{l} / \mathrm{min}$, (e) $0.80 \mathrm{l} / \mathrm{min}$ and (f) $1.20 \mathrm{l} / \mathrm{min}$.
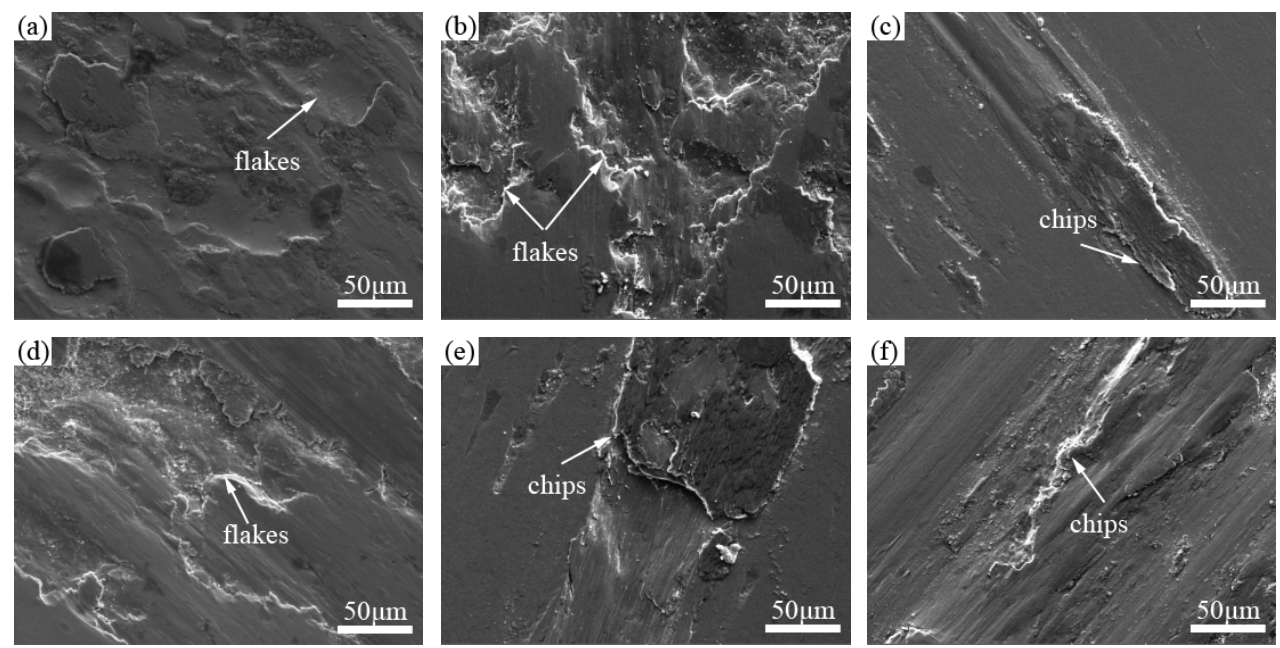

Fig.9 SEM imagines of the worn surface at sliding distance of $3200 \mathrm{~m}$ for the different $\mathrm{NH}_{3}$ addition rate (a) Q/T, (b) $0.28 \mathrm{l} / \mathrm{min}$, (c) $0.40 \mathrm{l} / \mathrm{min}$, (d) $0.60 \mathrm{l} / \mathrm{min}$, (e) $0.80 \mathrm{l} / \mathrm{min}$ and (f) $1.20 \mathrm{l} / \mathrm{min}$.

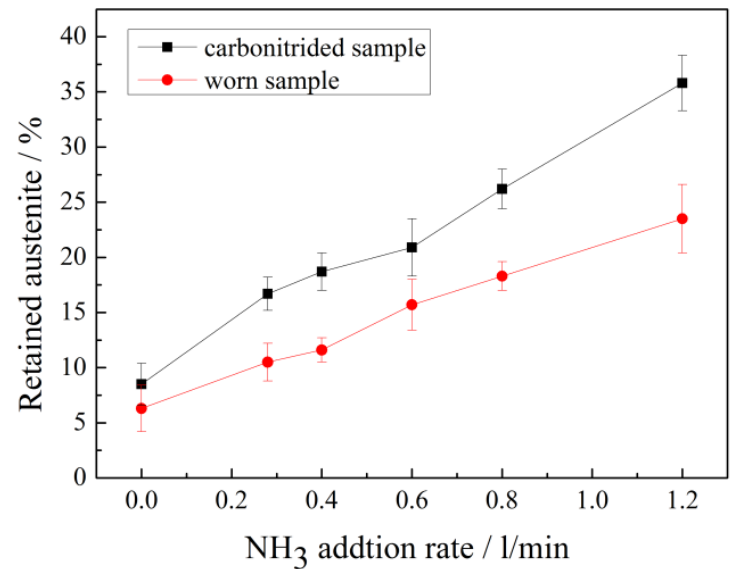

Fig 10 The fraction of RA in carbonitrided and worn specimens treated with different $\mathrm{NH}_{3}$ addition rate. 
